\title{
Evaluation of the Heat Balance of Driving Axle in Winter Conditions
}

\author{
${ }^{1}$ Aleksej Yu. Barykin, ${ }^{2}$ Rayaz Kh. Takhaviev, ${ }^{3}$ Almaz D. Samigullin \\ ${ }^{1-3}$ Kazan Federal University \\ Email:samigullin86@mail.ru
}

Received: 20 ${ }^{\text {th }}$ August 2019, Accepted: $3^{\text {th }}$ September 2019, Published: $31^{\text {st }}$ October 2019

\begin{abstract}
The article discusses the effective operation of the truck's drive axle under the influence of extreme environmental factors. The influence of temperature and mobility of ambient air, storage and operation of the car is considered. A description of the loading conditions of the drive axle parts is given. The authors developed a classification of external and internal parameters that determine the load of parts. The analysis of the influence of transmission oil, as a determining factor in the friction conditions of parts. The main modes of friction of parts that occur during operation in difficult conditions, including the modes of viscous and semi-dry friction, are considered. It is proposed to take into account the loading mode of the drive axle parts with the engine and transmission during changes in fuel supply, gear shifting, and vehicle control. The paper proposes analytical relationships that describe the processes of heat transfer during the operation of the bridge and take into account the state of the environment. The method developed by the authors of the article for experimental research of the thermal state of the bridge during operation is described. Information is given on the distribution of temperature measuring points over various sections of the bridge, which provides an objective picture of temperature gradients in various conditions. The characteristics of the measuring device used during the road tests are described. The necessity of continuous monitoring of the thermal state of the bridge during operation at low temperatures of atmospheric air is substantiated. Recommendations on ensuring the optimal thermal state of the drive axle during operation in winter conditions are offered.
\end{abstract}

\section{Keywords}

Winter Operation of the Car, Drive Axle, Gear Oil, Road Tests, Temperature Gradient, Thermal State Monitoring.

\section{Introduction}

Trucks are designed for operation in a wide variety of road and environmental conditions. There is a need for the delivery of goods by road to remote regions, including in the winter season. In such conditions, the requirements for the reliability of all units and systems of the car, the durability of the parts and the reliable operation of the friction units increase significantly.

Winter operation of cars is a complex of factors, the content of which may vary significantly for different countries and regions [1,2]. The organization of cargo transportation in the regions of Siberia is hampered by low air temperatures [3]. It is also necessary to take into account the speed of movement of air masses, in some cases - the unsatisfactory condition of winter roads and insufficient driver qualifications.

The way the car is stored is essential. When using open parking lots or closed unheated garage spaces, cars need pre-start preparation. Most often, such training is limited to preheating the engine, in some cases, the gearbox, battery and hydraulic power steering [4]. Transmission units - cardan transmission, final drive and drive axle - are left without thermal effects. A cold start to the drive axle can lead to a reduction in service life and sudden failure.

Recently, scientific papers have appeared, the authors of which indicate the need for the heat treatment of individual transmission units. However, heating at the beginning of the movement is insufficient for normal operation during operation on the line.

The causes of failures and breakdowns should be sought in the unsatisfactory condition of the parts of the main gear and differential, partially losing strength properties during subcooling. In addition, the properties of gear oil thickening upon cooling change. Regardless of the brand of oil used, its viscosity cannot remain constant with a significant change in temperature [5]. An increase in the viscosity of the oil reduces the efficiency and leads to a deterioration in lubricating properties in gears and sliding bearings [6]. For the drive axle of the generally accepted design, the sliding friction units are the friction pairs "satellite - differential spider", "satellite - the differential surface of the differential cup" and "semiaxial gear - the bearing surface of the differential cup". In these friction nodes, significant power losses during satellite rotation are possible, which, in turn, can cause an increase in internal friction in the differential and an increase in the degree of blocking of the inner wheel drive [7].

An additional influence on the loading of parts of the drive axle can be exerted by the driver by making sudden gear changes and braking [8,9]. You should also take into account the dynamic loads on the bridge parts, which are caused by macro-roughness of the supporting surface. These factors should be taken into account even at relatively low values of the estimated parameters since here the combined effect of temperature and power loads is important. Impact, which under normal conditions would not lead to breakage, may be critical for a supercooled component. Also, it is necessary to take into account the change in the properties of the suspension at low ambient temperatures. Increasing the stiffness of the suspension is also not conducive to the normal operation of the nodes of the drive axle. 
For an objective assessment of the condition of the drive axle during operation in winter conditions, it is necessary to analyze and classify significant impact factors within the framework of the accepted natural-technical system. Then you should evaluate the direction and quantify the thermal processes that occur during the interaction of parts of the drive axle with the environment.

\section{Methods}

The analysis of the loading of the driving axles of trucks by the authors showed that it is necessary to take into account the following significant factors of the operation process in winter conditions:

- ambient air temperature;

- $\quad$ ambient air mobility;

- viscosity-temperature characteristics of gear oil;

- the degree of linear and volume expansion (compression) of the material of the drive axle parts when their temperature changes;

- $\quad$ amplitude and frequency of dynamic loads in the transmission;

- $\quad$ amplitude and frequency of dynamic loads from the supporting surface.

The importance of taking ambient temperature into account is obvious. However, for a number of regions of the Russian Federation, it is especially relevant. According to the source [3], it was found that the average values of the absolute minimums of January temperature for most regions of the European part of the Russian Federation are in the range -25 ... $-34{ }^{\circ} \mathrm{C}$, for the regions of Western and Eastern Siberia - in the range - $38 \ldots-54{ }^{\circ} \mathrm{C}$. It can be concluded that a significant decrease in the temperature of the parts of the drive axle and gear oil before the operation in winter is very likely.

The combination of the influence of negative temperature with air blowing significantly complicates the operating conditions of the drive axle. This issue was studied in more detail in [10], which provides information on road tests on the temperature state of driving bridges and other nodes when driving in winter conditions. In [11], it was noted that according to the results of observations for a significant part of the territory of the Russian Federation, combinations of ambient temperatures are possible - up to $-60 \ldots-65{ }^{\circ} \mathrm{C}$ and wind speed - up to $30 \mathrm{~m} / \mathrm{s}$, while the winter period for different regions is $200 \ldots 300$ days a year.

For comparison, the recommended values of operating temperatures for the respective classes of gear oils can be given. In accordance with the data of [5], the viscosity class $S A E 80 \mathrm{~W}$ sets the maximum permissible operating temperature -26 ${ }^{0} \mathrm{C}$, while the pour point of such an oil corresponds to $-30{ }^{\circ} \mathrm{C}$. Viscosity grade $S A E 75 \mathrm{~W}$ sets the maximum permissible operating temperature $-40{ }^{\circ} \mathrm{C}$. It should be noted that the use of gear oil that meets the weather conditions does not mean ensuring ideal working conditions for the drive axle. Also, the operating temperature ranges of the used oil brands, as a rule, take into account the average values of weather conditions.

Resizing parts due to cooling or heating is critical to the operational reliability of the drive axle assemblies. The problem is that with linear or volumetric deformation of parts, the clearances and tightnesses of movable and fixed joints established by operational requirements change. If for gears this may be less important, since there is a certain range of acceptable sizes for them, then for connections with a guaranteed interference fit, the situation looks different.

For the drive axle, the most critical connection is the preload of the main gear provided in the radial direction of the pinion shaft [12]. The established value of the axial force in the joint allows maintaining stable stiffness of the main gear, which is extremely necessary for the correct position of the contact spot in the gearing of gears [13]. A decrease in axial force will lead to a decrease in stiffness and a possible rapid failure of the gears. An increase in axial force in excess of the set values is also undesirable since it additionally loads the bearing assembly of the final drive and reduces its durability. Here, the material of the parts providing guaranteed interference, their elastic properties and the dependence of the elasticity of the parts on temperature are of great importance.

The impact from the driver and the road can be taken into account in the calculations using correction factors that reflect the degree of increase in the load on the parts of the drive axle. The application of such a technique using correction dynamic coefficients was considered in [9].

Increasing the viscosity of transmission oil leads to an increase in friction losses and a decrease in the overall efficiency of the transmission. As a result, additional resistance to movement leads to an increase in fuel consumption.

Based on the analysis of the loading conditions of the driving axles, tasks and methods for further research were formulated. The need for road tests of driving axles in winter conditions was established to assess the temperature conditions of parts and the need for heating using on board heat sources. A technique is proposed for measuring and controlling the temperatures of the drive axle at the nodal points to limit the necessary thermal effect. The task of creating a calculation method that allows us to estimate the quantitative heat transfer parameters of the drive axle with the environment has been set.

\section{Results and Discussions}

The authors of the article prepared and conducted road tests of the leading bridges of the KAMAZ-65115 dump truck to establish temperature gradients during winter operation. Tests were conducted in the Zakamye region of the Republic of Tatarstan, on paved roads. 
As a result of the tests, it was found that during the operation of the car the drive axle heats up and cools very unevenly, and the degree of unevenness depends on the intensity of loading parts. In fig. 1 is a lead bridge heat trace illustrating the distribution of temperature gradients.

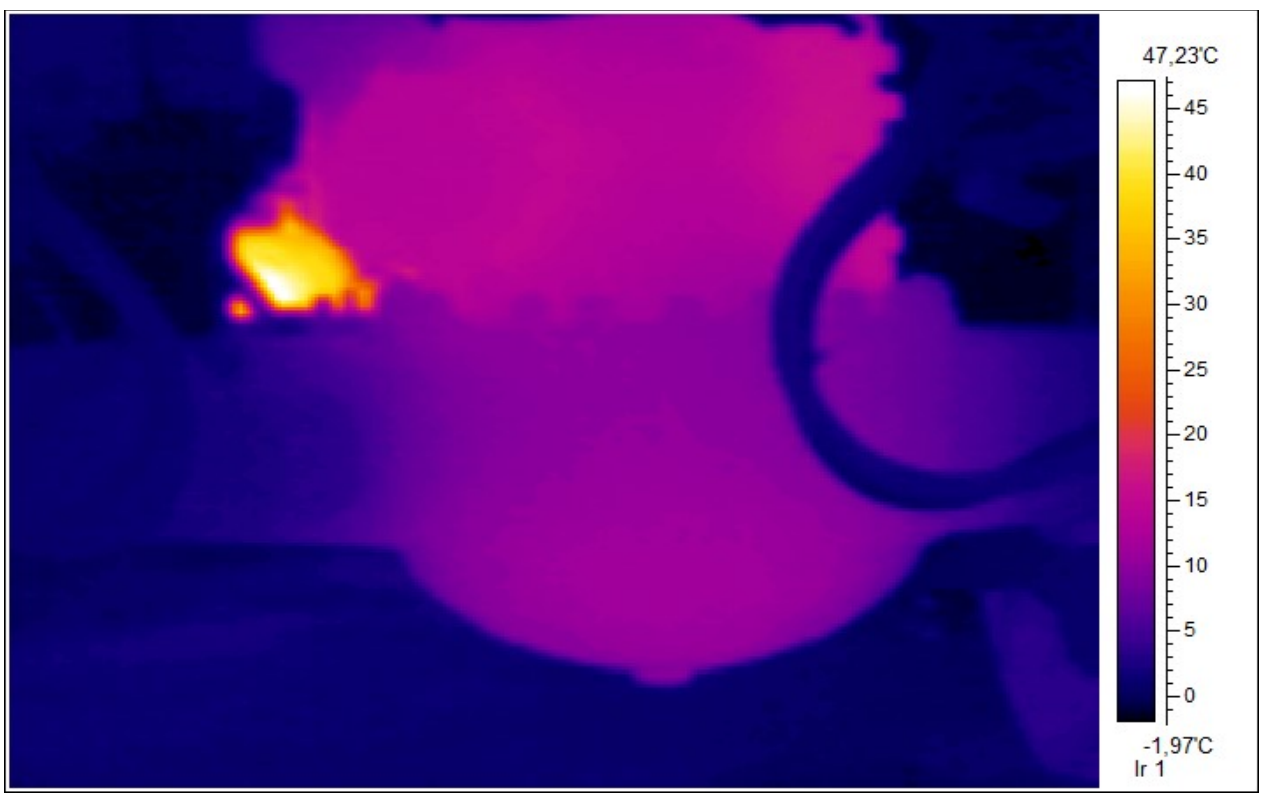

Figure 1: Thermogram of the Drive Axle of the Car

Based on given road tests was developed the procedure of the estimation of the parameters of the heat exchange of drive axle with the environment [14]. Based on this procedure, the authors carried out the analysis of heat exchange conditions of the main drive with the environment. It is established, in particular, that the amount of heat consumed by the heat transfer of the main transmission with the environment should be determined by the formulas:

$Q=\alpha_{m g} \cdot k_{a m} \cdot S_{m g} \cdot \Delta T_{c e} \cdot t_{\mathrm{int}}$,

$\Delta T_{c e}=T_{a v}-T_{e n v}$

where $\alpha_{m g}$ - the coefficient of heat transfer from the crankcase of main drive to atmospheric air; $k_{a m}-$ the coefficient, which considers a change in the intensity of heat exchange because of the mobility of atmospheric air; $S_{m g}$ - the area of the external surface of the crankcase of main drive taking into account of technological openings and apertures; $\Delta T_{c e}$ - a calculated difference in temperatures of main drive and of environment; $t_{\text {int }}$ - the estimated time of heat exchange; $T_{a v}$ - the mean volumetric temperature of main drive during the period from the beginning to the completion of heat exchange; $T_{\text {env }}$ - free-air temperature.

The obtained formulas make it possible to give the quantitative assessment to one of the influential factors of heat exchange and to establish the need for applying a preheating drive axle under the assigned operating conditions.

\section{Summary}

Based on the results of a study of the operational condition of the driving axles of a truck, the following conclusions can be drawn.

Details of the drive axle, which is operated in winter conditions, experience significant temperature and dynamic loads. As road tests show, the degree of loading of individual parts substantially depends on their location in the crankcase and beam of the drive axle. Significant temperature gradients of the drive axle arising during its operation are established. The heating of the main gear and differential, which occurs during the onset and continuation of the movement, is insufficient to ensure a rational temperature range. Most of the time the main gear, differential and axle shafts operate in adverse conditions, described by the complex effect of temperature and dynamic factors.

There is an objective need to use an on-board device that automatically implements the function of thermal preparation and further periodic heating of the drive axle when driving in winter operating conditions. 


\section{Conclusions}

The study of the loading of the drive axle when driving at low temperatures is an urgent scientific task, the solution of which will ensure the high durability and reliability of the car. The construction of a method for calculating heat transfer indices allows a rational choice of the range of application of the heating device for the drive axle and to increase the durability and reliability of the automobile transmission.

\section{Acknowledgments}

The work is performed according to the Russian Government Program of Competitive Growth of Kazan Federal University.

\section{References}

[1] Yu. L. Bakurevich, S.S. Tolkachev, F.N. Shevelev. Car operation in the North. - M.: Transport, 1973. - 180 pages.

[2] N.V. Semenov. Car operation at low temperatures. - M.: Transport, 1993 - 190 pages.

[3] Weather and Climate [Electronic source]: - URL: http://www.pogodaiklimat.ru/archive.php (access mode 04/03/2019).

[4] Car Technical Operation: Manual for Higher Education Institutions. 4 th edition, revised and enlarged / Kuznetsov Ye. S., Boldin. A. P, Vlasov. V. M, et al. Edited by Ye. S. Kuznetsov. - 4 th edition. - M.: Nauka, 2001. - 535 pages.

[5] D. Klamann. Lubricants and Other Related Products. Synthesis. Properties. APPLICATION. International Standards: translated from English / under the editorship of Yu. S. Zaslavskiy. - M.: Chemistry, 1988. - 488 pages.

[6] A.T. Kulakov. Providing normal conditions of lubricating of diesel engine during its operation / A.T. Kulakov, A.A. Gafiyatullin, E.P. Barylnikova. // IOP Conference Series: Materials Science and Engineering. - Volume 69, Issue 1, 2014, No. 012027

[7] A. Yu. Barykin. Evaluation of Performance Characteristics Influence on Blocking Properties of Small Friction Differentials / Materials of International Scientific and Technical Conference "Innovative Mechanical Engineering Technology, Equipment, and Materials - 2013" and the Forum "Increasing Competitiveness and Energy Efficiency of Mechanical Engineering Companies under WTO Conditions". V. 1. - Kazan: Foliant, 2013. pp. 18-34.

[8] I.R. Mavleev, I.I. Salakhov, D.I. Nuretdinov. Modular heavy-duty truck transmission // IOP Conference Series: Materials Science and Engineering. - 2018. - Vol.386, Is.1. - Art. No. 012018.

[9] N.V. Gusakov, I.N. Zverev and etc. Car design. Chassis. - M.: MAMI, 2000 - 528 pages.

[10] V.F. Platonov. All-wheel drive cars - 2nd ed. reslave. and add. - M.: Mechanical Engineering, 1989. - 312 pages.

[11] V.L. Rogovtsev, A.G. Puzankov, V.D. Oldfield. The device and operation of vehicles. - M.: Transport, 1991. 432 pages.

[12] M.M. Mukhametdinov. Studying the Intensity of Pre-Load Drops in KamAZ Final-Drive Anti-Friction Bearings // In Mechanical Engineering: Design, Engineering, Calculation, and Manufacturing and Repair Technology (Mashinostroyeniye: design, engineering, engineering, and technology overhaul and production). Proceedings of All-Russian Research and Practice Conference. - Izhevsk, Izhevsk State Technical University, 2012. pp. 113-114.

[13] V.V. Lyandenburskiy. V. Diagnostics of Truck Axle Drive Gears / V. V. Lyandenburskiy [et al.] // Problems of Quality and Operation of Motor Vehicles: Operation and Development of Motor Vehicles [Text]: Materials of the Xth International Virtual Scientific and Technical Conference May 15, 2015, Penza / [editorial board: E. R. Domke (responsible editor) et al.]. - Penza: PGUAS, 2015. Cognitive Brain Research, 2005, 24(2), pp. 199-205.

[14] A. Yu. Barykin. The research of thermal processes of the automobile chassis / A.Yu. Barykin, R.Kh.Takhaviev, A.D. Samigullin // International Journal of Mechanical and Production Engineering Research and Development. - 2018. - Vol. 8, Special Issue 8, Oct 2018, pp. 458-464. 